\title{
Scale variability of atmospheric surface layer fluxes of energy and carbon over a tropical rain forest in southwest Amazonia 1. Diurnal conditions
}

\author{
Celso von Randow, Leonardo D. A. Sá, Prasad S. S. D. Gannabathula, \\ Antonio O. Manzi, and Paulo R. A. Arlino \\ Laboratório Associado de Meteorologia e Oceanografia (LMO), Centro de Previsão de Tempo e Estudos Climáticos \\ (CPTEC), Instituto Nacional de Pesquisas Espaciais (INPE), São José dos Campos, Brazil
}

Bart Kruijt

Alterra-Green World Research, Wageningen, Netherlands

Received 16 January 2001; revised 10 October 2001; accepted 27 November 2001; published 4 September 2002.

[1] The aim of this study is to investigate the low-frequency characteristics of diurnal turbulent scalar spectra and cospectra near the Amazonian rain forest during the wet and dry seasons. This is because the available turbulent data are often nonstationary and there is no clear spectral gap to separate data into "mean" and "turbulent" parts. Daubechies- 8 orthogonal wavelet is used to scale project turbulent signals in order to provide scale variance and covariance estimations. Based on the characteristics of the scale dependence of the scalar fluxes, some classification criteria of this scale dependence are investigated. The total scalar covariance of each 4-hour data run is partitioned in categories of scale covariance contributions. This permits the study of some statistical characteristics of the scalar turbulent fields in each one of these classes and, thus, to give an insight and a possible explanation of the origin of the variability of the scalar fields close to the Amazonian forest. The results have shown that a two-category classification is the most appropriate to describe the kind of observed fluctuations: "turbulent" and "mesoscale" contributions. The largest contribution of the sensible heat, latent heat, and $\mathrm{CO}_{2}$ covariance contributions occurs in the "turbulent" length scales. Mesoscale eddy motions, however, can contribute up to $30 \%$ of the total covariances under weak wind conditions. Analysis of scale correlation coefficient $\left[r\left(T_{\mathrm{v}} q\right)\right]$ between virtual temperature $\left(T_{\mathrm{v}}\right)$ and humidity $(q)$ signals shows that the scale patterns of $T_{\mathrm{v}}$ and $q$ variability are not similar and $r\left(T_{\mathrm{v}} q\right)<1$ for all analyzed scales. Scale humidity skewness calculations are negative during the dry season and positive during the wet season. This suggests that different boundary layer moisture regimes occur during the dry and wet seasons. INDEX TERMS: 3307 Meteorology and Atmospheric Dynamics: Boundary layer processes; 3322 Meteorology and Atmospheric Dynamics: Land/ atmosphere interactions; 3379 Meteorology and Atmospheric Dynamics: Turbulence

Citation: von Randow, C., L. D. A. Sá, P. S. S. D. Gannabathula, A. O. Manzi, P. R. A. Arlino, and B. Kruijt, Scale variability of atmospheric surface layer fluxes of energy and carbon over a tropical rain forest in southwest Amazonia. 1. Diurnal conditions, $J$. Geophys. Res., 107(0), 8062, doi:10.1029/2001JD000379, 2002.

\section{Introduction}

[2] In literature, accuracy of turbulent flux estimation using the eddy-correlation method is often overlooked or neglected, although its importance is evident, as discussed by [Shuttleworth et al., 1984; Mahrt, 1991, 1998; Vickers and Mahrt, 1997; McNaughton and Laubach, 2000], among others. It is a complex problem and contains several uncertainties associated with the nature of turbulence itself [Lumley and Panofsky, 1964; Wyngaard, 1992; McNaughton and Laubach, 2000]. This can be aggravated when measurements are made under certain peculiar conditions,

Copyright 2002 by the American Geophysical Union. 0148-0227/02/2001JD000379\$09.00 such as on towers or aircrafts, over complex surfaces, or under transient conditions [Mahrt, 1998], in the context of disturbed surface layers [McNaughton and Laubach, 2000] or disturbed wet tropical boundary layers [Garstang and Fitzjarrald, 1999]. Two main sources of imprecision in turbulent flux estimation could be stressed: the first one is result of the errors associated with the measurements themselves, and the second comes from the way in which eddy-correlation method is used. In this work we discuss the second aspect of the problem, by investigating questions related to the measurement of turbulent fluxes under nonstationary conditions or over nonhomogeneous surfaces and the dependence of flux calculations on the choice of cutoff frequency (or averaging period) used. 


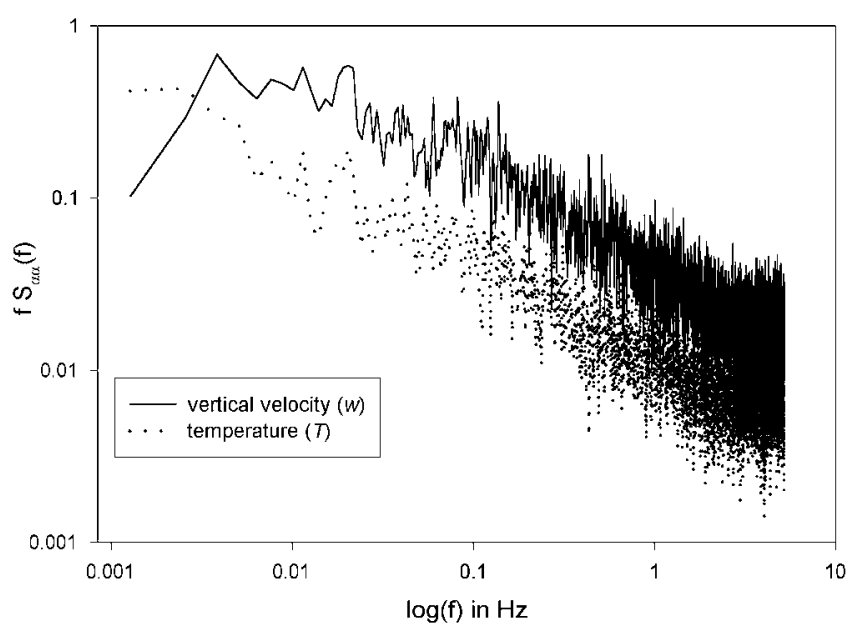

Figure 1. Fourier power spectra of vertical wind velocity component ( $w$, solid line) and virtual temperature $\left(T_{\mathrm{v}}\right.$, dotted line) at arbitrary units, measured from 1000 to 1200 UT (local time), on day 98, over Rebio Jaru forest.

[3] This imprecision in flux estimation appears when the power spectra of turbulent variables, such as $\mathrm{w}$ (vertical wind velocity) sampled at 1-hour scale does not show a clear spectral gap (see Figure 1). This problem was discussed by Lumley and Panofsky [1964, p. 45], on their classical study about atmospheric turbulence structure. They have identified scenarios where the autocorrelation function does not tend to zero with time, in such a way that the determination of integral scales sometimes becomes a particularly difficult task. It is evident that turbulent signals under such conditions leads to difficulties in defining correct averaging periods and fluctuations [Hildebrand, 1991; Mahrt, 1998]. Two major objections could be raised against the current practice concerning the validity of the stationarity and horizontal homogeneity hypotheses of the atmospheric boundary layer (ABL) turbulent fields. The first one results from the fact that the power spectra of turbulent fluctuations extend to large scales of motion, such as mesoscale ones, whose existence is connected to perturbations introduced by low-frequency motions [McNaughton and Laubach, 2000]. The computed turbulence variables are strongly dependent on the sampling period used. The second complication is associated with the factors regarding the variability imposed on the flow by external forcing such as the roughness of the terrain [McNaughton and Laubach, 2000], the existence of complex distributions of sources or sinks of scalars at the surface [Brutsaert, 1998], the effects originating from the top of the ABL [Mahrt, 1991], and so on.

[4] Sun et al. [1996], based on the characteristics of scale dependence, proposed partitioning the total flux into turbulent, large-eddy, and mesoscale fluxes due to motions on scales smaller than $1 \mathrm{~km}$, between 1 and $5 \mathrm{~km}$, and greater than $5 \mathrm{~km}$, respectively. In order to explain these scale dependent characteristics of flux, McNaughton and Laubach [2000] proposed a different three-class scheme, based on the attempts of Kader and Yaglom [1990] to generalize the classical Monin-Obukhov Similarity Theory (MOST). According to McNaughton and Laubach [2000], three different scaling regimes could act on the surface layer turbulent exchanges: an inner-layer scaling (ILS), an outerlayer scaling (OLS) and a combined scaling (CS). Each one of these regimes would explain the characteristics of turbulent power spectra and cospectra in specific regions and their classification depends on height and frequency. The OLS components are associated with "inactive" turbulence and ILS components with "active" turbulence in the sense proposed by Townsend's hypothesis about turbulence atmospheric structure [Townsend, 1976]. Further, according to McNaughton and Laubach [2000], if the power spectra of active and inactive components of turbulence were separated by a spectral gap, there would be no interactions between the components. On the other hand, if there is no obvious spectral gap, there would be a matching region with a slope of -1 and an absence of $-5 / 3$ power law (for $u, v$, and scalar variables, but not for w-wind velocity component) corresponding to the CS region. Williams et al. [1996] in their study about flux airborne measures in the intertropical convergence zone ABL have presented detectable basic structural differences between eddies containing the high and low wave number fluxes. The turbulent characteristics associated with the higher wave numbers show more coherent and repeatable behavior than the ones associated with low wave numbers. This is because the low frequency is not only controlled by the atmospheric boundary layer similarity parameters, but also by phenomena that are generated outside of the boundary layer environment.

[5] Each one of these classes should have a specific parameterization to represent the subgrid fluxes in models of simulations of ABL. This is particularly difficult for large eddies and mesoscale motions situations. Other class-separation criteria have also been proposed. Howell and Mahrt [1994] also studied the scale dependence of surface fluxes. Using the Haar wavelet transform they decompose the turbulent signals into 4 classes, the three cited above, and a "fine scale" class, corresponding to very small-scale motions, with nearly isotropic characteristics.

[6] The classes established by Sun et al. [1996] and Williams et al. [1996] refer to tropical oceanic boundary layer that in some specific situations (in the vicinity of large cloud cluster systems, for example) do not show a clear gap in the power spectra [Williams et al., 1996] and are similar to the ABL over Amazon rain forest during the wet-season [Garstang and Fitzjarrald, 1999]. According to Garstang and Fitzjarrald, as in the tropical marine boundary layer, the tropical wet season ABL above the rain forest could be characterized as a disturbed state of the boundary layer, which presents peculiar inter-scale links properties. It has qualitatively different characteristics than that observed in undisturbed boundary layers and exhibits some peculiar tropospheric phenomena, such as outflows, which play important role on vertical flux transport and in defining vertical exchange processes time-scales. Under these conditions, it is hard to characterize an upper limit to the ABL, whose thermodynamic characteristics are strictly associated with the nature of the convection in the humid troposphere. It is important to mention that the exchanges of heat and moisture on the top of $\mathrm{ABL}$ also appear to influence the variability of turbulent scalar variables measured at the surface [Mahrt, 1991; Williams et al., 1996; Garstang and Fitzjarrald, 1999]. Mahrt [1991] showed that, depending on the ABL moisture regime, different characteristic scales of 
potential virtual temperature and humidity are present in some turbulent processes close to the surface.

[7] Even disregarding the influence of the top of ABL, at least four physically distinct factors may contribute to the variability of measurements at surface: (1) local circulation induced by horizontal heterogeneity of the terrain [Mahrt et al., 1994], which is expected to exist in Rebio Jaru site (this study) due the existence of "fish-bone pattern" strips of alternating forested/deforested areas surrounding the reserve and also due to the wavy pattern of the vegetated crown top; (2) contribution from updrafts and downdrafts to surface fluxes, associated with the very strong convective activity present in Amazonia [Garstang and Fitzjarrald, 1999]; (3) contributions from coherent structures in turbulent flow, with specific characteristics over vegetated covers, particularly in scalar fluxes [Collineau and Brunet, 1993; Gao and Li, 1993; Brunet and Irvine, 2000]; (4) the effects of slow wind direction and wind strength variation on scalar transport processes near the ground [McNaughton and Laubach, 2000]. The last variations are identified with the concept of "inactive" turbulence [Townsend, 1976].

[8] These factors can result in important contributions to the total fluxes by low frequency eddy motions, as reported by Sakai [2000]. The author found that for a summer-time signal, obtained above a midlatitude deciduous forest in Canada, large eddies with periods ranging from 4 to $30 \mathrm{~min}$ might contribute about $17 \%$ to total surface fluxes of heat, water vapor and $\mathrm{CO}_{2}$. It is likely that these contributions would not be taken into account if the fluxes were calculated by the currently popular averaging-periods procedures. This is because these usual sampling time intervals are too short to resolve the larger eddies present in the flow [Mahrt, 1998]. Sakai [2000] has also found that short-averaging periods might underestimate daytime $\mathrm{CO}_{2}$ fluxes at standard towers by $10-40 \%$, depending on wind speed conditions.

[9] In this work we analyze turbulent data measured at Amazon rain forest during LBA 1999 wet-season campaign and during 2000 dry season period. The measuring heights, $62 \mathrm{~m}$ and $67 \mathrm{~m}$, are likely to be in a surface transition sublayer. During daytime, low-frequency contributions to eddy-correlation turbulent fluxes were often present. We apply wavelet transform to project the data on scales and calculate scale covariances similar to the ones used by Howell and Mahrt [1994] and Katul and Parlange [1994]. We use the Daubechies-8 wavelet [Daubechies, 1992] to decompose turbulent signals of vertical wind velocity $(w)$, virtual temperature $\left(T_{\mathrm{v}}\right)$, and humidity $(q)$ and $\mathrm{CO}_{2}$ concentration $(c)$. In spite of some restrictions concerning the feasibility of its applications [Treviño and Andreas, 1996], wavelet analysis is a powerful tool to analyze turbulent signals [Farge, 1992; Katul and Parlange, 1994]. Using the scale-projected signals, we then identify and partition the fluxes in the Amazonian atmospheric boundary layer.

\section{Site Description and Deployed Instruments}

[10] During the 1999 Wet Season in Amazonia, several activities of the LBA Project (Large Scale BiosphereAtmosphere Experiment in Amazonia) took place at the biological reserve of Jaru (Rebio Jaru), located about $100 \mathrm{~km}$ North of Ji-Paraná, Rondonia, Brazil [Silva Dias et al., 2002]. Rebio Jaru is a terra firme forest reserve owned by the Brazilian Environmental Protection Agency (IBAMA). In the predominant wind direction (moving clockwise from the north west to south-south east), the fetch condition is mainly of an undisturbed forest for tens of kilometers. However, in the other directions, it is much less (about $800 \mathrm{~m}$ ). The Ji-Paraná River forms the western boundary of the reserve. On the other side of the river the rain forest has been progressively cleared during the last 25 years. The cleared region has a very peculiar fish-bone pattern, which alternate patches of forest and of degraded land, and extends several kilometers to the south.

[11] In the Rebio Jaru reserve, canopy has a mean height of $35 \mathrm{~m}$; however, some of the higher tree branches have heights up to $45 \mathrm{~m}$. Andreae et al. [2002] give details of vegetation at this site. At the end of 1998, a new $60 \mathrm{~m}$ tall micrometeorological tower was built at this site $\left(10^{\circ} 4.706^{\prime} \mathrm{S} ; 61^{\circ} 56.027^{\prime} \mathrm{W}\right.$, at the height of $145 \mathrm{~m}$ A.S.L.), within the collaboration of two subprojects: LBA/ WETAMC (first LBA major wet season Atmospheric Mesoscale Campaign [Silva Dias et al., 2002]) and LBA/ EUSTACH (European Studies on Trace Gases and Atmospheric Chemistry [Andreae et al., 2002]). An extra mast of $7 \mathrm{~m}$ was built later at the top of this tower.

[12] Two data sets were used on this work. The first one (data set A) is composed by wind velocity, temperature, humidity and $\mathrm{CO}_{2}$ concentration measurements made between days 93 (3 April) and 98 (8 April) of 1999, and between days 234 (21 August) and 244 (31 August) of 2000, with a 3-D sonic anemometer (Solent A1012R, Gill Instruments), together with an infrared gas analyzer (LI6262, LICOR Inc.), both recording data at a sampling rate of $10.4 \mathrm{~Hz}$. These sensors were installed approximately $20 \mathrm{~cm}$ apart from each other. This data were obtained at the height of $62.7 \mathrm{~m}$, and is part of long term measurements of surface fluxes supported by the LBA/EUSTACH project. The second data set (B) is composed by turbulent data collected from day 31 (31 January) to 60 (1 March) of 1999, during WETAMC campaign, with a different 3-D sonic anemometer (CSAT3, Campbell Scientific Inc.) installed at the height of $67 \mathrm{~m}$ above the forest floor, measuring at a sampling rate of $16 \mathrm{~Hz}$. No humidity or $\mathrm{CO}_{2}$ concentration measurements were available during this period of data set B. The sonic anemometers measure the three wind velocity components $(u, v, w)$ and virtual air temperature $\left(T_{\mathrm{v}}\right)$, and the IRGA measures the concentration of water vapor $(q)$ and $\mathrm{CO}_{2}(c)$ in the air. Data quality control was done using the QC pack software of Vickers and Mahrt [1997]. Records with bad data points, instrument dropouts, poor resolution and abrupt changes are flagged and then examined visually. Bad data records were not used in the analysis.

\section{Scale Variability Analysis Theoretical Elements 3.1. Determination of Power Spectra and Cospectra Low-Frequency Ends of the Turbulent Variables}

[13] The Fourier energy spectrum has been one of the most familiar techniques for analysis of signals. Indeed, many of the traditional methods work in the Fourier space most of the time. The Fourier energy spectrum $E(k)$ of the real function $f(x)$ is defined by

$$
E(k)=\left|f^{*}(k)\right|^{2} \quad k \geq 0
$$


where $f^{*}(k)$ is the Fourier transform, given by

$$
f^{*}(k)=\int_{-\infty}^{+\infty} f(x) e^{-i k x} d x
$$

[14] The so-called "spectral gap" usually appears in power spectra of turbulent variables measured at middle and high latitude sites over uniform terrain and provides the necessary information about a good choice of the sampling segment size (time duration of measurements to flux determination). It also gives information on the temporal scale where the variables should be decomposed into mean and fluctuation parts. Although it is broadly accepted that the spectral gap exists, at least in a statistical sense, on temporal scales close to 1 hour [Lumley and Panofsky, 1964; Stull, 1988], there are situations when is hard to observe a clear gap, in intervals up to hundred of minutes [Sun et al., 1996; Williams et al., 1996; Mahrt, 1998; McNaughton and Laubach, 2000].

[15] Most of the power spectra observed over Rebio Jaru with data measured during morning and afternoon times show variance spread over a wide range of frequencies, without any obvious spectral gaps, even when the sampling sizes were increased to several hundreds of minutes. Figure 1 displays the power spectral density of vertical wind velocity component and virtual temperature signals measured from 1000 to $1200 \mathrm{~h}$ (local time) on day 98. This difficulty in determining a clear-cutoff frequency were observed both in wet and dry season periods and motivated the authors to use the methodology based on wavelet transforms, a mathematical tool which allows spectral analyses of nonstationary data, to analyze the scale variability of surface fluxes over this site.

\subsection{Wavelet Transforms}

[16] The wavelet transform (WT) is a powerful mathematical analysis tool, which permits an evolutionary spectral study of turbulent atmospheric signals [Daubechies, 1992; Farge, 1992]. WT is similar to, but an extension of Fourier analysis. WT is computationally similar in principle to Fast Fourier Transform (FFT). The FFT uses cosines, sines and exponentials to represent a signal, and is most useful for representing stationary functions. Since many 1-D and 2-D signals display nonlinear, chaotic, intermittent or fractal behavior, Fourier analysis is less suitable for analyzing such signals. Wavelets offer a more adequate method to analyze complex signals as they decompose such signals into contributions of different scales as well as different locations.

[17] The following material is also discussed by Katul and Parlange [1994] and the main points are presented here for completeness.

[18] WT is classified under two broad categories: (1) continuous WT, and (2) discrete WT. Daubechies [1992, p. 7] further classifies the discrete WT as (1) redundant discrete systems (also known as frames) and (2) orthonormal wavelet expansions. For analysis of turbulence measurements, discrete orthonormal WT is preferable since it is suitable to provide nonredundant decomposition information and it permits to obtain an inverse WT. The discrete WT is the representation of a given signal $f(t) \in \mathrm{L}^{2}(\mathrm{R})$ using a set of functions which are the scaled and shifted versions of a single function $\psi(t) \in \mathrm{L}^{2}(\mathrm{R})$, called the mother wavelet.
The function $\psi(t)$ has to satisfy the admissibility condition $\left(\int_{-\infty}^{+\infty} \psi(t) d t=0\right)$ to be a wavelet.

[19] As shown by Daubechies [1992, p. 10], using a logarithmic uniform spacing for the scale discretization with increasingly coarser spatial resolution at larger scales, a complete orthogonal wavelet basis can be constructed with

$$
\psi_{[j]}^{(m)}(y)=a_{0}^{-m / 2} \psi\left(\frac{y-j b_{0} a_{0}^{m}}{a_{0}^{m}}\right),
$$

where $m$ and $j$ are variable scale and position indices, respectively, $a_{0}$ is the base of the dilation, $b_{0}$ is the translation length in units of $a_{0}^{\mathrm{m}}$, and $(m)$ is used as a scale index (not to be confused with power $m$ ). The simplest and most efficient case for practical computations is the dyadic arrangement $\left(a_{0}=2\right.$ and $\left.b_{0}=1\right)$. All scales along octaves $2^{m}$ and translations along $2^{m} j$ contribute to the construction of $f\left(\mathrm{t}_{i}\right)=f(j)$ using

$$
f(j)=\sum_{m=1}^{m=\infty} \sum_{i=-\infty}^{i=+\infty} W^{(m)}[i] g^{(m)}\left[i-2^{m} j\right],
$$

where $g^{(m)}[i]$ is a discrete version of the continuous wavelet $\psi(t)$ at scale $m$, and the wavelet coefficients $W^{(m)}[i]$ are obtained from the signal, by the following convolution

$$
W^{(m)}[i]=\sum_{i=-\infty}^{i=+\infty} g^{(m)}\left[i-2^{m} j\right] f(j),
$$

and they satisfy the conservation of energy condition

$$
\sum_{j=-\infty}^{+\infty} F(j)^{2}=\sum_{m=1}^{m=+\infty} \sum_{i=-\infty}^{i=+\infty}\left(W^{(m)}[i]\right)^{2} .
$$

[20] In general, the number of observations is finite and the summations in the above equations do not extend to infinity. If $N=2^{M}$ is the number of observations (i.e., $N$ is an integer power of 2), the scale index $m$ then varies from 1 to $M=\log _{2}(N)$ and the position index at scale $m$ varies from 1 to $N \times 2^{-m}$. Note that this definition implies that as the scale increases, the spatial resolution becomes much coarser (e.g., at $m=1$, we have $N / 2$ coefficients, at $m=2$ we have $N / 4$ coefficients, at $m=M$ we have 1 coefficient).

[21] Just as the Fourier transform can be computed using the Fast Fourier Transform (FFT), the discrete wavelet transform can be computed using the fast filtering scheme of Mallat [1989]. The wavelet coefficients are computed using a pair of dyadic orthogonal filters called Quadrature Mirror Filters (QMF), which are related to the mother wavelet and the scaling functions. The QMF filter associated with the scaling function yields an approximate or smoothed version of the original signal at successive resolutions, while the output of the filter associated with the wavelet gives the details of the signal. The outputs of the approximation filter are cascaded to give the different scales. The detail signals at stage $m$ and location $i$ are the wavelet coefficients $W^{(m)}[i]$ (for more details, see Katul and Parlange [1994]).

\subsection{Wavelet Statistics}

[22] Some statistical tools that utilize the wavelet coefficients can be deduced for characterizing the contribution 
of different scales to the total variances and covariances of turbulent signals. The variance of a signal $f(t)$, in terms of its wavelet coefficients, is deduced from (6) using

$$
\operatorname{var}(f)=N^{-1} \sum_{m=1}^{m=M} \sum_{i=1}^{i=N}\left(W_{f}^{(m)}[i]\right)^{2}
$$

where $N$ is the number of observations (multiples of 2), $M$ is $\log _{2}(N), m$ is the scale index, and $i$ is the position index. Assuming that the observations are sampled every $d y$ meters (or in the case of observations sampled at a fixed point, with the flow passing through the sensors, one can analyze in terms of timescales or use Taylor's hypothesis), the total energy $T_{E}$ contained in scale $R_{m}=$ $\left(2^{m} d y\right)$ is given by

$$
T_{E}=N^{-1} \sum_{i=1}^{i=2^{M-M}}\left(W_{f}^{(m)}[i]\right)^{2}
$$

This energy can be directly interpreted as the contribution from scale $R_{m}$ to the total variance of the signal.

[23] Similarly, the covariance of two signals $f_{1}(t)$ and $f_{2}(t)$ can be expressed as

$$
\operatorname{Cov}\left(f_{1}, f_{2}\right)=N^{-1} \sum_{m=1}^{m=M} \sum_{i=1}^{i=N} W_{f 1}^{(m)}[i] W_{f 2}^{(m)}[i]
$$

and scale contribution to total covariance can be analyzed using

$$
\operatorname{Cov}^{(m)}\left(f_{1}, f_{2}\right)=N^{-1} \sum_{i=1}^{i=2^{M-m}} W_{f 1}^{(m)}[i] W_{f 2}^{(m)}[i]
$$

\section{Results and Discussion}

[24] In order to project transient signals on selected scales, the turbulence time series of data set A (B), were divided into overlapping records of 131,072 $(262,144)$ data points, that correspond to approximately 3.5 (4.5) hours, recovered from the data sets following a time step of 1 hour. These record lengths were chosen to provide better analyses of low frequency motions, and because under diurnal conditions, turbulent signals seldom presented spectra or cospectra low frequency end at scales larger than 2 to 3 hours. Each record of vertical wind velocity component $(w)$, virtual air temperature $\left(T_{\mathrm{v}}\right)$, humidity $(q)$ and $\mathrm{CO}_{2}$ concentration $(c)$ were then decomposed into 16 scales $(15$ scales, in case of data set B), using the Daubechies-8 WT. This WT is a discrete orthogonal wavelet and the cospectra based on this kind of detail separation can be interpreted as fluxes decomposed into values computed from moving averages [Howell and Mahrt, 1997]. Since our interest is mainly on the flux computation, the exact shape of the wavelet is not very important. Various wavelets were examined and there were very little differences in the scale variances and covariances, a result similar to the one obtained by Katul and Parlange [1994] for turbulent data measured at atmospheric surface layer under several stability conditions. We have therefore chosen the Daubechies- 8 wavelet as a compromise between very short abruptly changing wavelets, like Haar, and smooth wavelets, such as Battle-Lemarie.

[25] Next, results and discussion are presented split in the following parts: (1) low-frequency time series analyses and range of validity Taylor's hypothesis; (2) scale variance of wind velocity $w$-component and scalars; (3) scale covariance analyses providing useful information about momentum and scalar turbulent fluxes; (4) separation of variances and fluxes into classes; (5) scale similarity regarding scalar fluxes and scale Bowen ratio analysis; (6) scale heat flux and mean horizontal wind speed relationship.

\subsection{Lower-Frequency Time Series Analyses and Taylor's Hypothesis Range of Validity}

[26] To perform our scale variability analysis, we address the range where Taylor's hypothesis (TH) is valid. Taylor's frozen turbulence hypothesis can be used to convert from timescales to length scales: the instruments installed on a fixed point permit one to obtain time records of the turbulent variables as the flow blows past the sensors with an a mean wind speed $\langle U\rangle$. Therefore, we can convert from time increments to space increments using

$$
y=\langle U\rangle t
$$

[27] To assess range of validity $\mathrm{TH}$ we used Wyngaard and Clifford [1977] test (here referred to as WC) in which the turbulent intensity $I_{u}\left(=\sigma_{u} /\langle U\rangle\right.$, where $\sigma_{u}$ is the standard deviation of the turbulent longitudinal wind velocity component and $\langle U\rangle$ is the mean wind velocity which impacts the measuring instrument) should not exceed 0.33 .

[28] According to our data analysis, in almost all 4-hour records the intensity of the turbulent signal $I_{u}$ follows the relation $I_{u}<0.33$ and so $\mathrm{WC}$ test for TH holds, for most of our data. The only situations in which WC test failed are those in which the wind velocity, averaged on the 4-hour period, was relatively small. These records were excluded from the analysis. After excluding the records where WC test fails, 23 records on wet season and 37 records on dry season were available for analyses, in data set A and 82 day time records in data set $\mathrm{B}$.

\subsection{Scale Variances}

[29] To perform an analysis on the scale contributions of different physical processes to total fluxes, the scale variances of $w, T_{\mathrm{v}}, q$ and $c$, were calculated for data set A, using (7), and then averaged during diurnal periods (9:00 to 17:00 h, L.T.). The first period, comprising days 93 to 98 of 1999 , is representative of late wet season, when the forest environment is likely to have higher soil moisture content and a more intensive convective activity, compared to the dry season. The second period analyzed uses days 234 to 244, in the dry season of 2000 . For comparison of scale variability, the energy contained in each scale $\left(T_{E}(m)\right)$ is normalized by the total variance of the signal. The seasonal variability of these spectral energy distributions, are shown in Figures $2 \mathrm{a}$ and $2 \mathrm{~b}$. In the former, we present the scale variances of $w$ and of scalar variables during the wet season. In the latter, we present the same variables, for the dry season. The scales are presented as eddy length scales, which were estimated using $\mathrm{TH}$. 

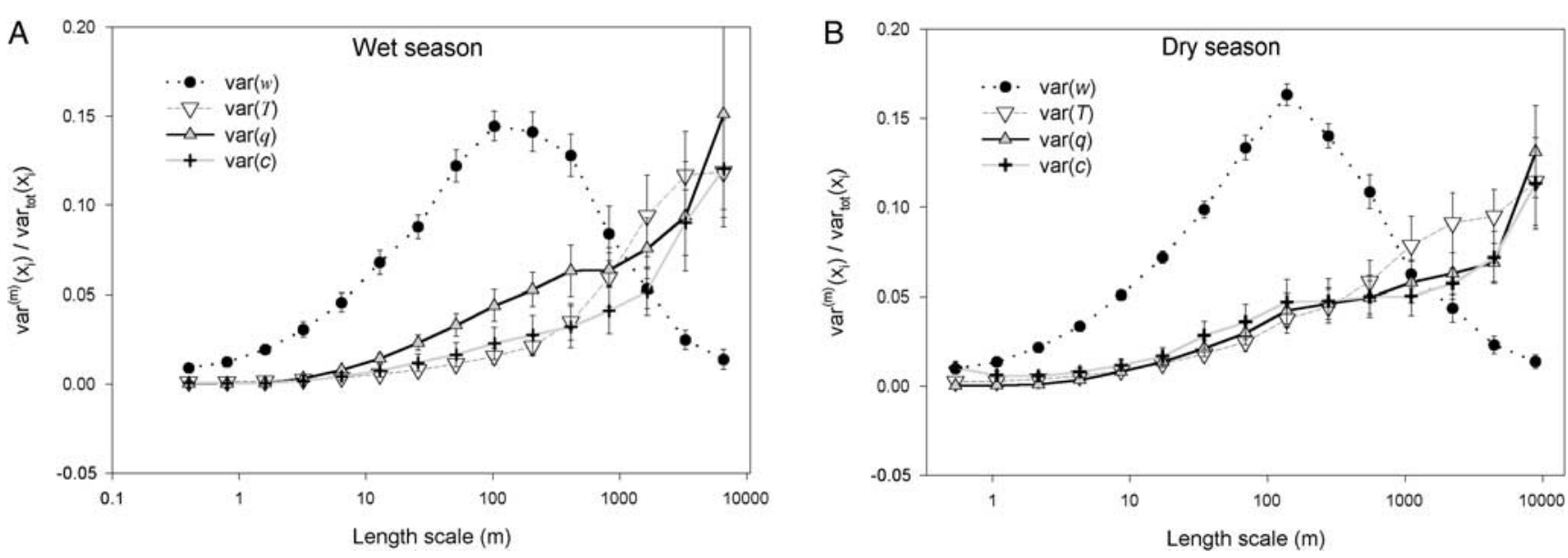

Figure 2. (a) Scale variances of vertical wind velocity $(w)$, virtual temperature $\left(T_{\mathrm{v}}\right)$, and humidity $(q)$ and $\mathrm{CO}_{2}$ concentrations $(c)$, averaged during diurnal periods (0900 to $1700 \mathrm{UT}$ ), over Rebio Jaru forest, for data collected from day 93 to 98 (wet season period). The error bars represent the $95 \%$ confidence level. (b) Same as Figure 2a, but for averages from day 234 to 244 (dry season period).

[30] The main differences observed between the two seasons are the following:

1. During dry season there are no significant differences among the shape of scalar variance curves along the full range of scales analyzed. Variances of $T_{\mathrm{v}}, q$ and $c$ show a nearly exponential pattern growing from very small values at small scales, to their largest values at mesoscale.

2. During the wet season period there are clear differences between scale variability of $q$-variance and of the other scalars variances. While $T_{\mathrm{v}}$-variance and $c$-variance show similar pattern as in the dry season, the $q$-variance still presents pronounced energy in scales ranging from 10 to $1000 \mathrm{~m}$, compared to larger scales, showing a nearly linear growth.

3. Regarding the differences between the scale variance of $w$ in dry and wet seasons, we observe that the scale variation patterns are similar during the two seasons, with the same maximum-energy range scale. Nevertheless, $w$ variances during dry season present a more pronounced peak on scales ranging from 100 to $300 \mathrm{~m}$ than the during wet season.

[31] These differences could be attributed to different dominant eddy structures in the dry and wet seasons. The investigation of the physical mechanisms which generate different eddy structures in the ABL lead many authors to propose physical criteria to characterize distinct atmospheric boundary layer regimes. One classification of them was proposed by LeMone [1976] and discussed by authors such as Mahrt [1991] and Garstang and Fitzjarrald [1999, p. 178].

[32] As possible mechanisms responsible by the seasonal $\operatorname{var}(q)$ differences we could take in consideration the remarks of Mahrt [1991] about boundary layer regime classes. As was demonstrated by him, within an unstable boundary layer and a relatively weak surface evaporation and drier air aloft, boundary layer top-down eddy motions could transport dry air from the entrainment layer down to the surface layer resulting in negative moisture skewness values there. This is in spite of positive temperature and vertical velocity skewness associated with warm moisture updrafts in the same region. An opposite situation occurs associated with greater surface evaporation regimes, where moisture skewness is positive near the surface. To investigate the existence of such a mechanism in Amazon forest ABL, we have calculated the scale skewness values of $q$ $\left(S_{q}\right)$ for wet and dry season periods. The skewness factor of the scalar $x$ at $m$-scale can be computed by

$$
S_{x}^{(m)}=\frac{\left\langle\left(W^{(m)}[i]\right)^{3}\right\rangle}{\left\langle\left(W^{(m)}[i]^{2}\right)\right\rangle^{3 / 2}} .
$$

[33] Our results, presented in Figure 3, show clearly that, in wet season, $S_{q}>0$ for all but three scales that, in dry season, $S_{q}<0$ for all but two scales. However, two of the scales in which $S_{q}>0$ for dry season and $S_{q}<0$ for wet season are the smallest ones and the results in this range are probably affected by very local phenomena related to

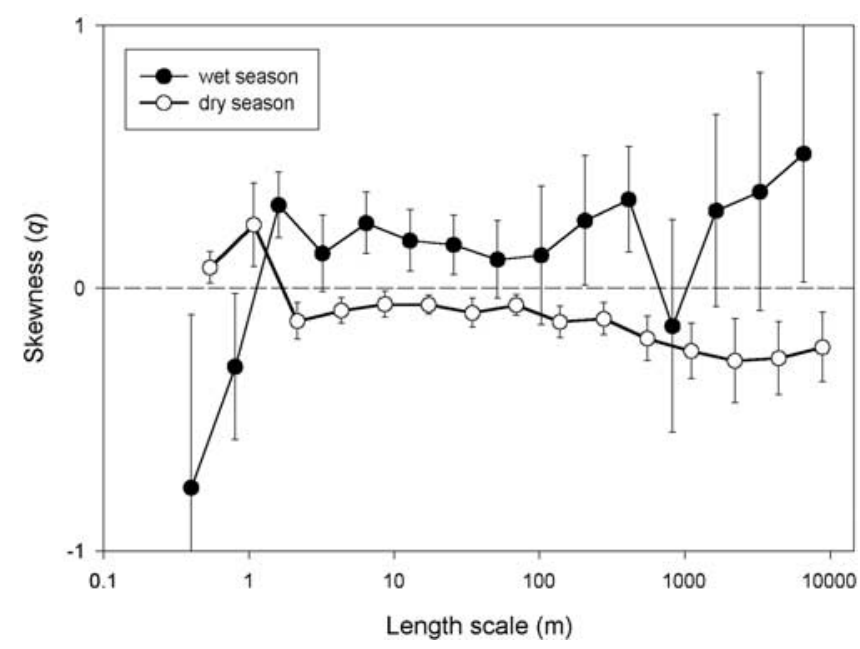

Figure 3. Scale skewness factor of humidity signals $\left(S_{q}\right)$ for the same periods as in Figure 2. 

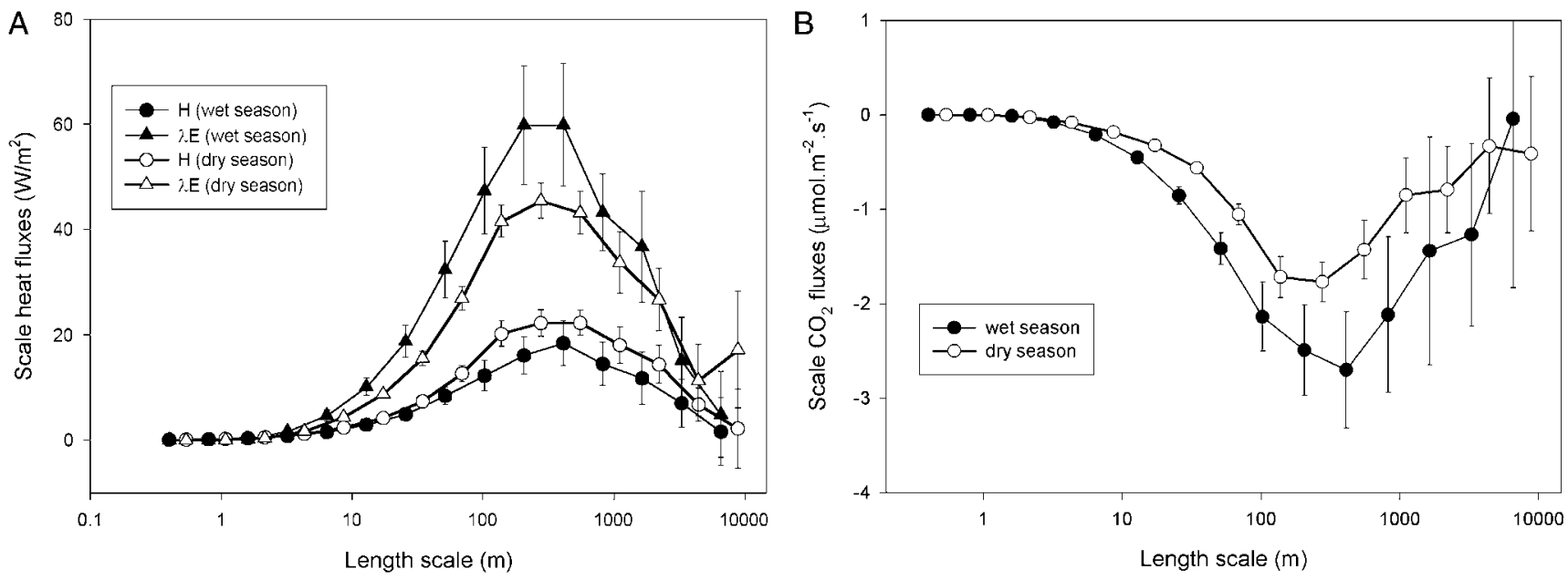

Figure 4. (a) Scale covariance contribution to fluxes of sensible $(H)$ and latent heat $(\lambda E)$ averaged for the same period as in Figure 2. Details are the same as in Figure 2. (b) Scale covariance contribution to $\mathrm{CO}_{2}$ fluxes, averaged for the same period as in Figure 2. Details are the same as in Figure 2.

physical roughness sublayer. It is also possible to observe that the dispersion $S_{q}$ is more pronounced in wet season comparatively to dry season. This higher dispersion in wet season period is probably related to the more transient character of the flow during this season. Figure 3 results probably explain the differences between $T_{\mathrm{v}}$ and $q$ fields arising from the humidity transport mechanisms proposed by Mahrt [1991], consequent of the entrainment-drying boundary layer or of boundary layer eddies which transport warmer, drier air toward the surface, a mechanism pointed out by Nicholls and Lemone [1980].

\subsection{Scale Fluxes}

[34] Scale covariance calculations of $w$ and scalars $\left(T_{\mathrm{v}}, q\right.$ and $c$ ) from the wavelet coefficients were carried out to assess the partial contribution of specific scales to the total fluxes of energy and carbon. Figure $4 \mathrm{a}$ shows this scale dependence for sensible $(H)$ and latent $(\lambda E)$ heat fluxes, and Figure $4 \mathrm{~b}$, for $\mathrm{CO}_{2}$ flux, averaged at the same periods as in Figure 2. We will discuss some aspects of the high and low frequency features of our results. On the smallest scales, corresponding to the fully developed turbulence inertial subrange, that should involve nearly isotropic motions, the fluxes are very small, although different from zero. Under certain conditions, anisotropy predominates in the lowest scales and the contributions to turbulent fluxes in this interval are not null. This has been analyzed by Katul et al. [1997] who investigated situations where large-scale anisotropy disturbs the inertial subrange isotropy. This could be an explanation for our results. From $10 \mathrm{~m}$ toward larger scales, the fluxes increase significantly, which shows a strong turbulent transport contribution to the total turbulent transport coming from this interval. Both sensible and latent heat fluxes, as well as $\mathrm{CO}_{2}$ flux, reach a maximum value at scales close to $400 \mathrm{~m}$ (corresponding to timescales of approximately $3 \mathrm{~min}$ ), and then decrease to smaller values at larger scales. The physical origins of these maximumenergy eddies in such scale interval are most likely related to convective processes which are typical of the Amazonian tropical boundary layer. Coincidentally, Gu et al. [2001] have recently presented evidences of cloud modulation of solar irradiance in a Amazonian pasture (located not far from our experimental site) associated with cloud gap patterns whose long time fluctuations are of the order of $3 \mathrm{~min}$, the same time-scale order that we have obtained in our results. This modulation of irradiance may be responsible for convective turbulence regimes during diurnal unstable conditions over Amazonia. Based on the work of Gu et al. [2001], we suggest that cloud gap effects represent the more important source of $w$-TKE in the Amazon forest (wet) convective boundary layer and this could explain, at least in part, the physical origin of our 3 min energy-peaks.

[35] The general pattern of heat and $\mathrm{CO}_{2}$ fluxes scale dependence is very similar considering wet and dry season periods. However, two seasonal differences are observed: (1) one is related to the available energy partition between sensible and latent heat flux (Figure 4a). During dry season the $H$ mean value increases and $\lambda E$ mean value decreases compared to mean values obtained during the wet season. This is an expected result since the dominant hydrology conditions during dry season lead to lower evapotranspiration and higher sensible heat fluxes from the vegetation to the atmosphere in this period, compared to wet season, in Amazonian forest; (2) the second, related to different $\mathrm{CO}_{2}$ diurnal uptake from the atmosphere by forest vegetation in wet and dry seasons, is clearly observed in Figure 4b. A similar seasonal behavior of $\mathrm{CO}_{2}$ diurnal fluxes was also observed by Malhi et al. [1998], over an undisturbed forest area in Central Amazonia. According to their measurements, the diurnal $\mathrm{CO}_{2}$ uptake by photosynthesis activity is apparently constrained by water availability, and therefore, the soil water stress observed during dry season lead to smaller $\mathrm{CO}_{2}$ assimilation by vegetation. This kind of water availability constraint is likely to diminish our diurnal $\mathrm{CO}_{2}$ flux measurements too.

[36] Although the largest amount of the energy and mass fluxes occur on turbulent scales lower or of the order of the $w$-spectral peak, larger scale eddy motions could generate important contributions to the total fluxes, during wet and dry seasons. According to our results, these low-frequency 
contributions to surface fluxes also show large variation among the various investigated data records, as we can see on Figures 4. This shows up by the estimated large sampling errors that are observed in this figure, at largest scales region.

\subsection{Variances and Fluxes Separated in Classes}

[37] There is no consensus in the literature with respect to categories in which the variances and fluxes might be classified regarding their scale dependence. Among the various classification schemes mentioned in our introduction, we will investigate two classification suggestions: the three classes proposed by Sun et al. [1996] and the two main classes proposed by Williams et al. [1996]. In this section we will investigate the feasibility of application of the above criteria. We will perform this based on the available measured variables to choose an appropriate classification scheme concerning scale dependence fluxes in the Amazonian ABL.

[38] We propose to assess the more adequate classification by both analyzing our earlier section results and investigating the scale dispersion of the flux calculations. To obtain such scale dispersions we calculate a normalized standard deviation of the scale flux (NSDF) by the expression:

$$
\operatorname{NSDF}_{(m)}=\frac{\operatorname{var}^{1 / 2}\left(\left(w^{\prime} x^{\prime}\right)_{(m)}\right)}{\operatorname{mean}\left(\left(w^{\prime} x^{\prime}\right)_{(m)}\right)}
$$

which is a ratio between the standard deviation of the calculated $m$-scale flux for scalar $x$ and the same variable mean value. In Figures $5 \mathrm{a}$ and $5 \mathrm{~b}$ we show estimations of $N S D F$ for sensible heat, latent heat and $\mathrm{CO}_{2}$ fluxes at wet and dry seasons, respectively.

[39] All the curves in both dry and wet seasons depict a clearly two general categories pattern with respect to scale variation of $N S D F$. In the first, associated with smaller scales range, there is no important variation of NSDF along the scales. In the second, associated with the larger scales, there is a clear increase of NSDF with length scale. Despite the fact that these shapes are the same for the two studied periods, the threshold length scale separating the two NSDF variability regimes in wet season is lesser than the one obtained in the dry season. We also observe that in all available situations, the curves for $(w T)$ and $(w q)$ present a very similar behavior, except for the largest scales analyzed. However, this is not true for $(w c)$ curve, whose two-regimes threshold occurs at length scales smaller than the ones for $(w T)$ and $(w q)$.

[40] After Sun et al. [1996], the existence of three distinct classes is suggested by the dependence of momentum flux calculations on both the cutoff length scale and flux averaging scale. As their measurements of momentum flux are nearly independent of flux averaging scale until scales close to $5 \mathrm{~km}$, this threshold would separate the lowfrequency components in two classes: "large eddies" and "mesoscale". However, based only on scale scalar flux behavior, a number of independent considerations from authors such as Williams et al. [1996] all suggest only one clear distinction isolating turbulent fluctuations from larger-scale variations. Our results confirm the existence of two main classes of scalar fluxes.
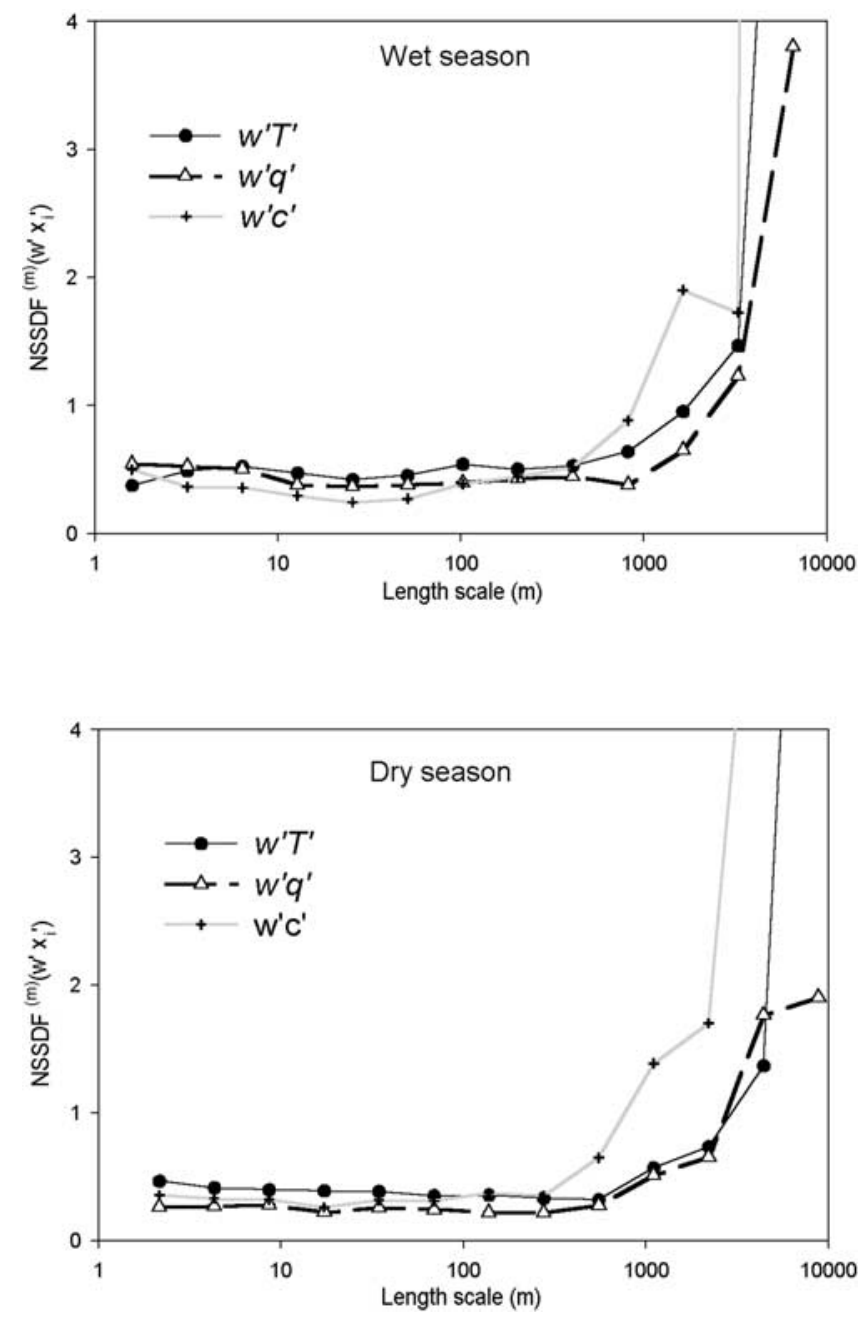

Figure 5. Normalized $m$-scale standard deviations of fluxes $(N S D F)$ for $w T_{\mathrm{v}}, w q$ and $w c$ scale covariances, calculated during the same periods as in Figure 2: (a) wet season; (b) dry season.

[41] These results led us to consider that a two-classes scheme for eddies containing fluxes is more appropriate to explain scale scalar flux variability in Amazonia than the Sun et al. [1996] three-classes scheme. Other aspects of the flux scale dependence issue will be discussed after next subsection.

[42] To provide quantitative information about the amount of flux contained in these two turbulence-pattern classes, we present Table 1. In this table we present the mean class and total heat fluxes, Bowen ratio, $\mathrm{CO}_{2}$ flux and variances of $w, T_{\mathrm{v}}, q$ and $c$ averaged during the two periods of data set A. About $28 \%$ of sensible heat and $27 \%$ of latent heat is transported by motions in scales higher than $800 \mathrm{~m}$, in the wet season, and these percentages are even slightly higher during dry season $29 \%$ and $30 \%$, for sensible and latent heat fluxes, respectively. For $\mathrm{CO}_{2}$ fluxes, the results are similar: $30 \%$ and $27 \%$ occur on large eddy motions, during wet and dry season periods, respectively. These calculations do not provide a true climatology of fluxes, which would require averaging over a much larger data set including a wider range of conditions, but provide a simple 
Table 1. Partition of the Total Surface Flux Contribution From Each One of the Two Scale Ranges for the Wet and Dry Seasons

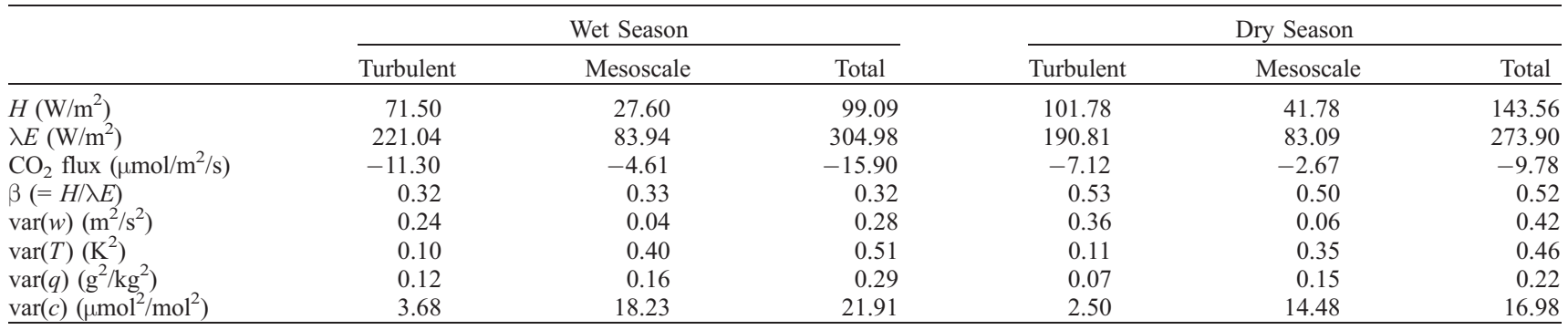

summary of the scale dependence of fluxes over Rebio Jaru forest. Our purpose here is to warn about the various phenomena that can influence the exchange processes on this disturbed ABL, as described by Garstang and Fitzjarrald [1999].

[43] An explanation of our results can be based on the conclusions presented by McNaughton and Laubach [2000] in their investigation about the consequences of the unsteadiness of the wind field on the scalar fields. According to them, the surface fluxes of temperature and humidity do indeed vary in step with low-frequency variations in the wind under certain nonhomogeneous surface conditions. Theoretically, they showed, that these low-frequency variations of wind would affect the values of the eddy-diffusivities for temperature and humidity in different ways. It is interesting to note that this kind of low-frequency wind velocity variability and that dissimilarity between $T_{\mathrm{v}}$ and $q$ fluctuations was also observed in Rebio-Jaru turbulent data. It is important also to keep in mind that our experimental site is in a rain forest strip, which is surrounded by deforested areas in a very peculiar "fish-bone" pattern. Such a nonhomogeneous boundary condition could generate mesoscale circulations that would explain our lowfrequency scalar fluxes.

\subsection{Temperature-Humidity Correlation and Bowen Ratio Scale Dependence}

[44] Studies about similarity or dissimilarity in the potential temperature and humidity fields in the ABL are well known [Moeng and Wyngaard, 1984; Hill, 1989] and provide useful information about external forcings acting on ABL borders. This is particularly interesting with respect to entrainment zone influences on boundary layer top and even on atmospheric surface layers [Mahrt, 1991]. The fact that under certain conditions, the structure of moisture fluctuations in the boundary layer is different from that of heat makes the comparison of the moisture and heat statistics an useful tool to obtain some more physical insight into the flux scale-dependence problem. In this section we will investigate two related subjects: the scale correlation coefficient between $q$ and $T_{\mathrm{v}}$ and the scale relationship between sensible and latent heat fluxes (Bowen ratio concept extended to a scale assessment). In Figure 6 we present the scale correlation coefficient between $T_{\mathrm{v}}$ and $q, r\left(T_{\mathrm{v}} q\right)$, plotted against its related length scale, for dry and wet seasons. Observing these results, it is clear that $r\left(T_{\mathrm{v}} q\right)<1$ for all analyzed scales: $r\left(T_{\mathrm{v}} q\right)=0$ at the length scales of the order of $1 \mathrm{~m}$ and increases until reach the $10 \mathrm{~m}$ length scale. This fast decrement of $r\left(T_{\mathrm{v}} q\right)$ curve for the smallest length scales close to $1 \mathrm{~m}$ is not expected, since at these scales the $q-T_{\mathrm{v}}$ cospectrum should behave as a $-5 / 3$ power law, rather than the much faster "normal cospectra" decrease [Andreas, 1987], and therefore the $r\left(T_{\mathrm{v}} q\right)$ should diminish only slowly with the length scale. However, our result might be attributed to the distance between the $T_{\mathrm{v}}$ and $q$ measuring probes (recall that $T_{\mathrm{v}}$ is measured by sonic anemometer and $q$ is measured by IRGA, whose structure device center and inlet tube entrance separation is of the order of $20 \mathrm{~cm}$ ). In such scales, $T_{\mathrm{v}}$ and $q$ turbulent signals must present an important phase-difference, what could justify the drastic fall observed in correlation coefficient values. From the scale of $10 \mathrm{~m}$ up to approximately $100 \mathrm{~m}, r\left(T_{\mathrm{v}} q\right)$ presents a nearly constant value of approximately 0.7 in the dryseason curve and of approximately 0.6 in the wet season curve. For the length scales greater than $100 \mathrm{~m}$, both $r\left(T_{\mathrm{v}} q\right)$ curves fall down until cross the zero-axis at a length scale of the order of $3 \mathrm{~km}$. From this point, they become negative. Starting from these results and based on the findings of Hill [1989] and De Bruin et al. [1999], one possible conclusion is that the atmospheric surface layer Monin-Obukhov Similarity Theory (MOST) does not hold for all investigated scale-ranges. We could formulate tentative explanations for the above results: (1) For the scales of the order of tens of meters, as the measurements were

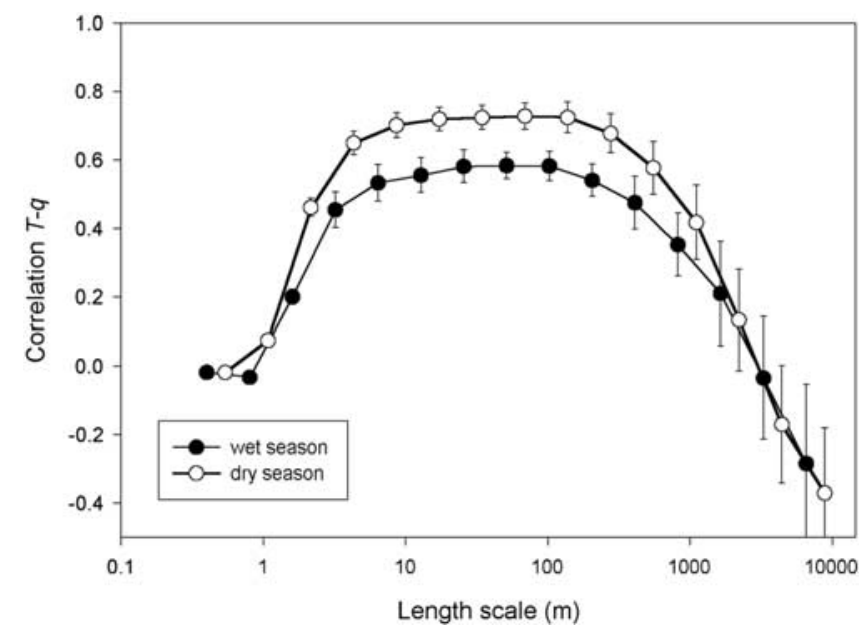

Figure 6. Scale correlation coefficient between virtual temperature $\left(T_{\mathrm{v}}\right)$ and humidity $(q)$, averaged for the same periods as in Figure 2. The error bars represent the 95\% confidence level. 


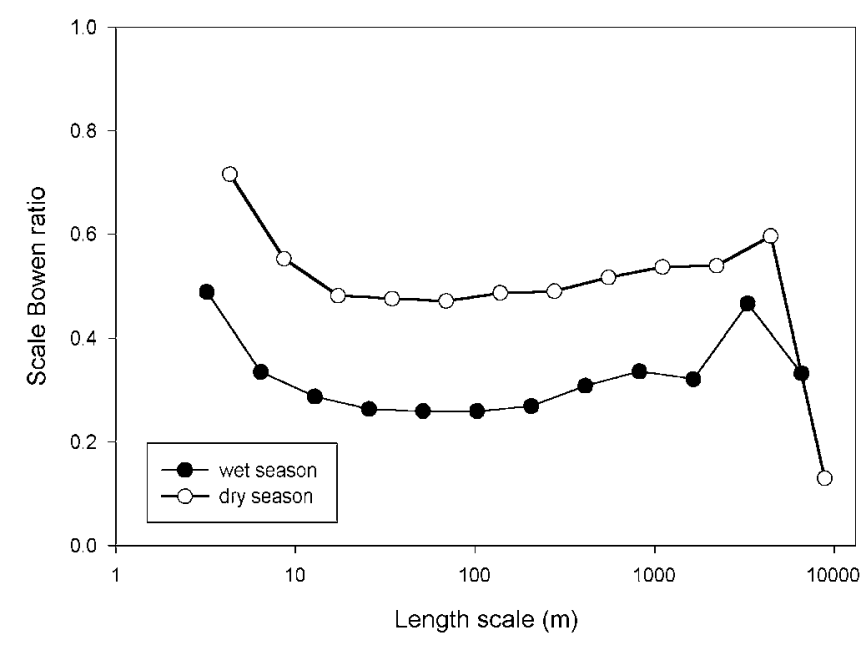

Figure 7. Ratio between scale sensible and latent heat fluxes, for the same periods as in Figure 2.

performed in a transition roughness sublayer, we indeed expect the failure of MOST [Raupach and Thom, 1981; Fitzjarrald et al., 1990]. So it is not surprising to obtain $0<r\left(T_{\mathrm{v}} q\right)<1$ in that region. (2) Another argument is based on the fact that there are topographically induced eddying as well as convectively induced eddying over the Rebio Jaru site. In this context, it would be useful for us to keep in mind the propositions of McNaughton and Laubach [2000] to explain the breakdown of MOST. As these authors have shown, some boundary conditions could introduce low-frequency wind speed fluctuations that generate dissimilarities between the eddy diffusivities for temperature and humidity. However, a more adequate explanation is that proposed by Mahrt [1991], concerning different boundary layer moisture regimes and their consequences for dissimilarity between $T_{\mathrm{v}}$ and $q$ fluctuations as we have already discussed in section 4.2.

[45] Bowen ratio $(\beta=H / \lambda E)$ is an important micrometeorological parameter that expresses how the surface available energy is shared between sensible and latent heat fluxes. Earlier investigations have already determined the overall characteristics of Bowen ratio variability in Amazon forest, such as studies by Sá et al. [1988]. According to $S a ́$ et al. [1988], the mean hourly $\beta$ calculated from values from 0700 to $1600 \mathrm{~h}$ varies from 0.05 to 0.85 . Such results are not in opposition with our mean values shown in Table 1. However, no systematic study has been carried out to assess the scale variability of this ratio in Amazon forest environment. From Figure 7 the shape of the scale variability of $H / \lambda E$ mean values is quite similar for dry and wet seasons and, as expected, the ratio is larger in the former than in the latter period. Except for length scales smaller than $10 \mathrm{~m}$ or larger than a few kilometers, the scale $\beta$ remains almost constant, around 0.3 during wet season and 0.5 during dry season, for each one of the investigated classes. The fact that $\beta$ presents discrepant values only at the edges of the investigated scale range may be due to (1) at the smallest length scales, as the fluxes are very small, the ratio between them can be strongly influenced by errors. Additionally, the fact that
$T_{\mathrm{v}}$ and $q$ measurements were performed $20 \mathrm{~cm}$ apart from each other can also introduce some errors there; (2) at the largest scales, we do not expect $r\left(T_{\mathrm{v}} q\right)$ to be statistically robust and the physical processes which determine the heat exchanges there are not related to inner boundary layer processes, but to peculiar external forcings, as discussed by Williams et al. [1996].

\subsection{Scale Heat Flux and Mean Horizontal Wind Speed Relationship}

[46] In Figure 8 we present $R_{m}$ (the ratio of scale $w T_{\mathrm{v}}$ covariance contributions of a specific eddy-pattern class to total sensible heat flux) as a function of the mean horizontal wind speed, $\langle U\rangle$, calculated from data set B (wet season period only). It is interesting to observe that the $R_{m}$ becomes more important as $\langle U\rangle$ enhances. The larger scale $R_{m}$ show a clear decrease with increasing $\langle U\rangle$. This seems to confirm our suggestion that contributions to the total heat flux are related to convective cloud gap patterns associated with updrafts, since they probably drive the main TKE generation mechanism in such region. For the low-frequency contributions, this would be attributed to the fact that the lower the mean speed, the greater the relative importance of the horizontal temperature gradient induced mesoscale motions to the overall wind field configuration. Starting from the assumption that these horizontal T-gradient are associated with fish-bone deforested strips and taking into consideration that wind direction often changes above Amazonian forest, a peculiar feature of the TKE generation in equatorial regions [Garstang and Fitzjarrald, 1999], we might expect important transient cellular motions under such conditions. Malhi et al. [1998] have pointed out the importance of distribution of wind directions in Amazonia, particularly concerning $\mathrm{CO}_{2}$ fluctuations. Some remarks of Mahrt [1998] might support other possible arguments to explain this results: (1) under weak large-scale flow and significant surface heating, the velocity fluctuations may

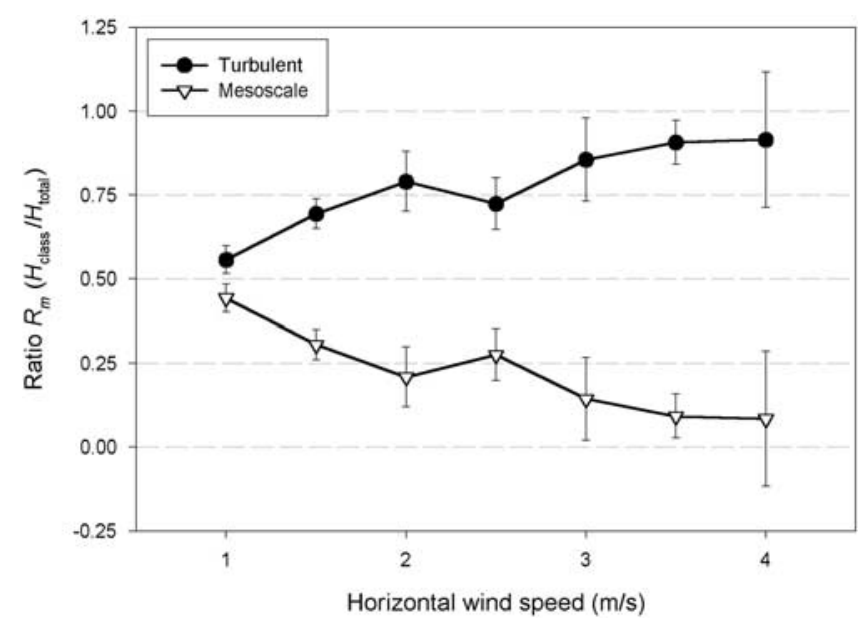

Figure 8. Ratio of sensible heat fluxes of two eddy-pattern classes to total sensible heat flux $\left(R_{m}\right)$, as a function of horizontal wind speed, calculated from day 31 to 60 over Rebio Jaru forest. The ratios were separated by wind speed classes and then averaged for each class. The standard errors are also shown. 
more closely approach pure updraft and downdraft motions and the special flow distortion effects under these situations would enhance low frequency motions; (2) the existence of stationary eddies, which could be attached to surface heterogeneity elements or could be slowly moving with weak winds.

\section{Summary and Conclusions}

[47] High frequency measurements $(10.4 \mathrm{~Hz}$, or $16 \mathrm{~Hz})$ of vertical wind velocity $(w)$, virtual temperature $\left(T_{\mathrm{v}}\right)$, humidity $(q)$ and $\mathrm{CO}_{2}$ concentration $(c)$ of air, obtained over Rebio Jaru tropical rain forest reservation, in south west Amazonia, were projected into 15 scales using the Daubechies- 8 wavelet transform (WT). The relative contributions of each scale to the total variances and covariances were then assessed, and normalized scale standard deviation of scalar fluxes were calculated. Based on this information, two main flux scale-dependence classes have been identified: (1) Turbulent scales, main scales of vertical turbulent transport of mass and energy in the atmospheric surface layer, ranging from the inertial subrange domain up to scales on the order of $800 \mathrm{~m}$ (or $6.5 \mathrm{~min}$ ); (2) Large scale eddies, motions involving eddies of scales on the order of or larger than the height of the ABL, involving processes not expected to be controlled only by $\mathrm{ABL}$ parameters.

[48] The variance of $w$ shows most of turbulent kinetic energy occurring on turbulent scales reaching a maximum on scales close to $300 \mathrm{~m}$ and decreasing to very low values on larger scales. Variances of $T_{\mathrm{v}}, q$ and $c$ show the higher values at mesoscale, indicating a likely high influence of mesoscale motions and convective systems that act on amazonian ABL on these data. Scale skewness calculations for humidity data were predominantly negative in dry season and positive in wet season. This suggests that during dry season top-down eddy motions could transport dry air from the entrainment layer down to surface layer leading to negative moisture skewness values, but this does not occur during wet season.

[49] The largest amount of the sensible heat, latent heat and $\mathrm{CO}_{2}$ fluxes occur on turbulent length scales below or of the order of the $w$-spectral peak scale. Larger scale eddy motions could, however, generate important contributions to the total fluxes. In addition, these low-frequency contributions to surface fluxes show large variation among the several investigated data records, and can be either positive or negative irrespectively of mean ABL gradient conditions. About $30 \%$ of scalar fluxes were found to be transported by motions on scales larger than $800 \mathrm{~m}$, on both wet and dry season studied periods.

[50] We also performed scale calculations of the correlation coefficients, $r\left(T_{\mathrm{v}} q\right)$, between virtual temperature $\left(T_{\mathrm{v}}\right)$ and humidity $(q)$. The results show that the turbulent fluctuations pattern of $T_{\mathrm{v}}$ and $q$ are not similar, and $r\left(T_{\mathrm{v}} q\right)<1$ for all analyzed scales.

[51] Acknowledgments. This work is part of The Large Scale Biosphere-Atmosphere Experiment in Amazonia (LBA) and was supported by the Fundação do Amparo à Pesquisa do Estado de São Paulo (FAPESP)/ Brazil-process 1997/9926-9. Thanks are due to Maria Assunção Faus da Silva Dias who is the coordinator of this research project. The authors are also grateful to INCRA/Ji-Paraná and to IBAMA/Ji-Paraná. C. von
Randow, P. Gannabathula are supported by a fellowship from Conselho Nacional de Pesquisa e Desenvolvimento Tecnológico (CNPq).

\section{References}

Andreae, M. O., et al., Towards an understanding of the biogeochemical cycling of carbon, water, energy, trace gases and aerosols in Amazonia: An overview of the LBA-EUSTACH experiments, J. Geophys. Res., 107, 10.1029/2001JD000324, in press, 2002.

Andreas, E. L., On the Kolmogorov constants for the temperature-humidity cospectrum and the refractive index spectrum, J. Atmos. Sci., 44, 23992406, 1987.

Brunet, Y., and M. R. Irvine, The control of coherent eddies in vegetation canopies: Streamwise structure spacing, canopy shear scale and atmospheric stability, Boundary Layer Meteorol., 94, 139-163, 2000.

Brutsaert, W., Land-surface water vapor and sensible heat flux: Spatial variability, homogeneity, and measurement scales, Water Resour. Res., 34, 2433-2442, 1998.

Collineau, S., and Y. Brunet, Detection of turbulent coherent motions in a forest canopy, Part 2, Time-scales and conditional averages, Boundary Layer Meteorol., 66, 49-73, 1993.

Daubechies, I., Ten Lectures on Wavelets, 357 pp., SIAM, Philadelphia, Pa., 1992.

De Bruin, H. A. R., B. J. J. M. Van Den Hurk, and L. J. M. Kroon, On the temperature-humidity correlation and similarity, Boundary Layer Meteorol., 93, 453-468, 1999.

Farge, M., The wavelet transform and its applications to turbulence, Annu. Rev. Fluid Mech., 24, 395-457, 1992.

Fitzjarrald, D. R., K. E. Moore, O. M. R. Cabral, J. Scolar, A. O. Manzi, and L. D. A. Sá, Daytime turbulent exchange between the Amazon forest and the atmosphere, J. Geophys. Res., 95, 16,825-16,838, 1990.

Gao, W., and B. L. Li, Wavelet analysis of coherent structures at the atmosphere-forest interface, J. Appl. Meteorol., 32, 1717-1725, 1993.

Garstang, M., and D. R. Fitzjarrald, Observations of Surface to Atmosphere Interactions in the Tropics, 405 pp., Oxford Univ. Press, New York, 1999.

Gu, L., J. D. Fuentes, M. Garstang, J. Tota da Silva, R. Heitz, J. Sigler, and H. H. Shugart, Cloud modulation of surface solar irradiance at a pasture site in southern Brazil, Agric. For. Meteorol., 106, 117-129, 2001.

Hildebrand, P. H., Error in eddy correlation turbulence measurements from aircraft: Application to HAPEX-MOBILHY, in Land Surface Evaporation-Measurement and Parameterization, edited by T. J. Schmugge and J.-C. André, pp. 231-243, Springer-Verlag, New York, 1991.

Hill, R. J., Implications of Monin-Obukhov similarity theory for scalar quantities, J. Atmos. Sci., 46, 2236-2244, 1989.

Howell, J. F., and L. Mahrt, An adaptative decomposition: Application to turbulence, in Wavelets in Geophysics, edited by P. Kumar and E. Foufoula-Georgiou, pp. 107-128, Academic, San Diego, Calif., 1994.

Howell, J. F., and L. Mahrt, Multirresolution flux decomposition, Boundary Layer Meteorol., 83, 117-137, 1997.

Kader, B. A., and A. M. Yaglom, Mean fields and fluctuation moments in unstable stratified turbulent boundary layers, J. Fluid Mech., 212, 637662,1990

Katul, G. G., and M. B. Parlange, On the active role of temperature in surface-layer turbulence, J. Atmos. Sci., 51, 2181-2195, 1994.

Katul, G., C.-I. Hsieh, and J. Sigmon, Energy-inertial scale interactions for velocity and temperature in the unstable atmospheric surface layer, Boundary Layer Meteorol., 82, 49-80, 1997.

LeMone, M. A., Modulation of turbulent energy by longitudinal rolls in an unstable boundary layer, J. Atmos. Sci., 33, 1308-1320, 1976.

Lumley, J. L., and H. A. Panofsky, The Structure of Atmospheric Turbulence, 239 pp., John Wiley, New York, 1964.

Mahrt, L., Boundary-layer moisture regimes, Q. J. R. Meteorol. Soc., 117, $151-176,1991$.

Mahrt, L., Flux sampling errors for aircraft and towers, J. Atmos. Oceanic Technol., 15, 416-429, 1998

Mahrt, L., J. I. Macpherson, and R. Desjardins, Observations of fluxes over heterogeneous surfaces, Boundary Layer Meteorol., 67, 345-367, 1994.

Malhi, Y., A. D. Nobre, J. Grace, B. Kruijt, M. G. P. Pereira, A. Culf, and S. Scott, Carbon dioxide transfer over a central Amazonian rain forest, J. Geophys. Res., 103, 31,593-31,612, 1998.

Mallat, S., A theory for multiresolution signal decomposition: The wavelet representation, IEEE Trans. PAMI, 11, 674-693, 1989

McNaughton, K. G., and J. Laubach, Power spectra and cospectra for wind and scalars in a disturbed surface layer at the base of an advective inversion, Boundary Layer Meteorol., 96, 143-185, 2000.

Moeng, C.-H., and J. C. Wyngaard, Statistics of conservative scalars in the convective boundary layer, J. Atmos. Sci., 41, 3161-3169, 1984.

Nicholls, S., and M. A. LeMone, The fair weather boundary layer in GATE. The relationship of subcloud fluxes and structure to the distri- 


\section{LBA}

bution and enhancement of cumulus clouds, J. Atmos. Sci., 37, 20512067, 1980 .

Raupach, M. R., and A. S. Thom, Turbulence in and above plant canopies, Аnnu. Rev. Fluid Mech., 13, 97-129, 1981.

Sá, L. D. A., Y. Viswanadham, and A. O. Manzi, Energy flux partitioning over the Amazon forest, Theor. Appl. Climatol., 39, 1-16, 1988.

Sakai, R. K., Observational study of turbulent exchange between the surface and canopy layer over several forest types, Ph.D. thesis, 182 pp., State University of New York at Albany, 2000.

Shuttleworth, J. W., et al., Eddy correlation measurements of energy partition for Amazonian forest, Q. J. R. Meteorol. Soc., 110, 1143-1162, 1984.

Silva Dias, M. A. F., et al., Clouds and rain processes in a biosphere atmosphere interaction context in the Amazon Region, J. Geophys. Res., 107, 10.1029/2001JD000335, in press, 2002.

Stull, R. B., An Introduction to Boundary Layer Meteorology, 666 pp., Kluwer Acad., Norwell, Mass., 1988.

Sun, J., J. F. Howell, S. K. Esbensen, L. Mahrt, C. M. Greb, R. Grossman, and M. A. LeMone, Scale dependence of air-sea fluxes over the western equatorial Pacific, J. Atmos. Sci., 53, 2997-3012, 1996.

Townsend, A. A., The Structure of Turbulent Shear Flow, 429 pp., Cambridge Univ. Press, New York, 1976.
Treviño, G., and E. L. Andreas, On wavelet analysis of nonstationary turbulence, Boundary Layer Meteorol., 81, 271-288, 1996.

Vickers, D., and L. Mahrt, Quality control and flux sampling problems for tower and aircraft data, J. Atmos. Oceanic Technol., 14, 512-526, 1997.

Williams, A. G., H. Kraus, and J. M. Hacker, Transport processes in the tropical warm pool boundary layer, Part 1 , Spectral composition of fluxes, J. Atmos. Sci., 53, 1187-1202, 1996.

Wyngaard, J. C., Atmospheric turbulence, Annu. Rev. Fluid Mech., 24, 205-233, 1992.

Wyngaard, J. C., and S. F. Clifford, Taylor's hypothesis and high-frequency turbulence spectra, J. Atmos. Sci., 34, 922-929, 1977.

P. R. A. Arlino, P. S. S. D. Gannabathula, A. O. Manzi, L. D. A. Sá, and C. von Randow, Laboratório Associado de Meteorologia e Oceanografia (LMO), Centro de Previsão de Tempo e Estudos Climáticos (CPTEC), Instituto Nacional de Pesquisas Espaciais (INPE), Av. dos Astronauts, 1758 PO Box 515, São José dos Campos, SP 12201-170, Brazil. (leo@cptec. inpe.br)

B. Kruijt, Alterra-Green World Research, Wageningen, Netherlands. 